\title{
Disordered eating in older people: some causes and treatments
}

\author{
Victor M. Aziz, Danika Rafferty \& Isabella Jurewicz
}

\begin{abstract}
SUMMARY
This overview considers causes of disordered eating, including eating disorders, in older people. Eating disorders are becoming more common in older adults and research has shown a related mortality of $21 \%$. The wide range of medical and pharmacological causes of weight loss in older people means that eating disorders may go undetected, occurring insidiously and surreptitiously.
\end{abstract}

\section{LEARNING OBJECTIVES}

- Be aware of the numerous causes of weight loss in older people, and understand that eating disorders are not about weight but about control

- Appreciate that physical and mental health problems and polypharmacy affect eating and weight

- Understand that successful management focuses on a combination of pharmacological and behavioural interventions

\section{DECLARATION OF INTEREST}

None

A preoccupation with eating, weight and physical appearance is entrenched in our society. Despite the fact that being of slightly higher weight is associated with little risk compared with being of low weight, an overview of research (Maine 2016) reports that:

- more than $20 \%$ of women over the age of 70 were dieting

- 70\% of women aged 30-74 were dissatisfied with their weight, despite being at a normal weight

- $62 \%$ of women over 65 wanted to lose weight, and $31 \%$ of them had dieted recently (even though $62 \%$ of those were of normal weight).

An online survey found that, over a 5-year period, $13 \%$ of women over 50 had eating disorder symptoms and 70\% reported weight loss (Gagne 2012).

There are four basic causes of weight loss in the elderly: anorexia, dysphagia, socioeconomic factors and weight loss despite normal intake.

Whatever the cause, weight loss in older people is known to predispose to muscle wasting, frailty, diminished immunocompetence, depression and increased susceptibility to diseases and disorders. These problems may themselves have an effect on food and fluid intake, creating a vicious circle. Identifying the cause of weight loss is therefore important, although eating disorders may be overlooked by healthcare professionals when assessing older adults (Dudrick 2013).

Reduced appetite is not an intrinsic part of older age, and clinicians should be aware of the increased number of people with eating disorders so that an earlier diagnosis can be made (Dudrick 2013).

Eating disorders should be considered in older people with weight loss, weight phobia or vomiting (Mangwet-Matzek 2006). Additional signs that might help identify an eating disorder include:

- an increase or decrease in weight over a short period (a loss of $5-10 \%$ in the past year may indicate a serious problem and should not be put down to a consequence of the normal ageing process)

- changes in behaviour, for example disappearing after a meal, using the toilet immediately after eating

- use of laxatives, diet pills or diuretics

- a desire to eat alone

- avoiding meals

- physical signs such as excessive hair loss, dental damage, heart or gastrointestinal problems

- anxiety and depression: these can be causes of weight loss, comorbid with eating disorders and signs of eating disorders.

Furthermore, just as with younger people, older people can have a distorted body image and engage in secretive purging (Mangwet-Matzek 2006; Dudrick 2013; Schaeffer 2016).

The case vignettes described in this article are typical of patients referred to the Service for Highrisk Eating Disorders (SHED) in South Wales (Box 1), but they do not represent any particular individual.

\section{Eating disorders}

Older people with eating disorders tend to belong to one of three categories: those with a chronic disorder from a much younger age, those that

\section{ARTICLE}

Victor M. Aziz is a consultant psychiatrist with Cwm Taf University Health Board. Danika Rafferty is a higher trainee in old age psychiatry (ST5) in the Wales Deanery. Isabella Jurewicz is a consultant psychiatrist with the Service for High-risk Eating Disorders (SHED), Cardiff and Vale University Health

Board. Correspondence DrV. M. Aziz, Consultant Psychiatrist, Cwm Taf University Health Board, OPCMHT, Ysbyty Cwm Cynon, New Road, Mountain Ash CF45 4DG, UK. Email: victoraziz@doctors.org.uk

\section{Copyright and usage}

(c) The Royal College of Psychiatrists 2017. 
BOX 1 The Service for High-risk Eating Disorders (SHED)

SHED is a tertiary service in South Wales that accepts referrals of people who have a high-risk eating disorder and need the support of a multidisciplinary team. For older people it works with community mental health teams and mental health services for older people. It covers two university local health boards, and a population of 47000 older people.

The service receives 2 or 3 referrals a year of patients over the age of 65 and referrals are characterised by typical triggers in older people, such as depression, the desire to change their life circumstances and the wish to gain control over an aspect of their life.

A typical elderly patient presenting to the service is female, has a BMI of 17.5, self-induced weight loss/ maintenance, a distorted body image ('morbid dread of fatness'), endocrine disorder (the average age of menopause in the UK is 51) and purging (older people are more likely to use laxatives than to induce vomiting). Older patients are more likely to have poorly fitting dentures, loss of smell/taste and memory difficulties. Their catabolic metabolism makes it easier to lose weight. Loss of role and bereavement are more common, as are poverty and an inability to shop for groceries and cook meals.

were identified and treated and the disorder has recurred, and those that first develop the disorder in later life. Understandably, the last group is the smallest and they may well have had some untreated disordered eating in their earlier life (Box 2) (Schaeffer 2016).

A study by the National Association of Anorexia Nervosa and Associated Disorders (based in the

B0X 2 Case vignette: weight loss with indeterminate cause

Anna is 73 years old and she has Parkinson's disease. Concerns were raised in the Parkinson's clinic, as her BMI had fallen to 13.75. She was referred to mental health services for older people (MHSOP), but the referral was initially rejected on the basis that she had no mental illness. Anna had been a highly driven professional, who described being bored with her current life. She had a history of depression and of mild body image problems in her youth. After a second referral she was accepted by MHSOP, and she benefited from the supportive approach of the MHSOP team, day hospital and dietetic support. Over 6 months she recovered to a BMI of around 18.

It was difficult to differentiate whether the original weight loss was self-induced or caused by depression, but it improved on mirtazapine.
USA) found that $86 \%$ of participants reported the onset of an eating disorder by the age of 20 , but only $50 \%$ reported being cured (Maine 2016). There is a particular challenge to treating chronic eating disorders (Gagne 2012). Mortality associated with anorexia nervosa increases with the duration of illness: it is $10 \%$ after 10 years of illness and 20\% after 20 years. Older bodies are also less able to recover from the strain and consequences of not eating (Schaeffer 2016).

The triggers for eating disorders have similarities across generations in that they are stress related, but the specific triggers in older adults are likely to be different. Older adults tend to experience loss and grieving; for example their children leaving home, ageing or death of their parents, death of a child, divorce, widowhood, chronic illness and natural signs of their own ageing. Triggers in younger adults tend to involve transitions (Maine 2016; Schaeffer 2016).

Eating disorders are not about weight and numbers but about control: an eating disorder is a coping mechanism. It therefore makes sense that someone who used diet and weight control as a coping mechanism as a young adult would revert to this in older age (Maine 2016; Schaeffer 2016).

Another risk factor for older people is body dissatisfaction as they move further from the cultural ideal of a young, thin, firm, unblemished body. Many people in Western countries measure their self-worth in terms of appearance, and often others measure them by appearance too (Marshall 2014). Despite the possibility of improved wisdom and skills with age, it seems that age does not always bring wisdom (ANRED 2016).

Although experts believe that diagnoses of eating disorder types in older adults fall evenly across the spectrum, some report that anorexia nervosa seems to be more common among the older patients they see. As Vivian Hanson Meehan, of the National Association of Anorexia Nervosa and Associated Disorders, said: 'that may be because it's easy to see when a person is getting thin, very thin, and maintains their thinness over great protestations, whereas bulimics are so good at hiding it' (Schaeffer 2016).

\section{Classification}

Until recently, eating disorders were classified in the DSM as anorexia nervosa, bulimia nervosa or eating disorder not otherwise specified (EDNOS) and, with the exception of amenorrhoea, the diagnostic criteria were the same for older and younger people (Schaeffer 2013). Older people with anorexia who were not amenorrhoeic would have been classified as having an EDNOS. 
BOX 4 Case vignette: atypical anorexia

Mary, a 67-year-old retired professional, stopped eating and socialising and reached a BMI of 14 . She denied losing weight on purpose, saying that she felt full and did not feel hungry or sick. She had been slim all her life and often ate little through the day. She denied having a body image disturbance. She ate in a highly controlled way, limiting her intake to an apple and a particular brand of vanilla nutritional milkshake taken at set times through the day. Her affect was indifferent and she lacked drive.

She met the diagnostic criteria for atypical anorexia. She has improved with psychotherapy and support from local eating disorder services and her BMI reached 16.5 .

However, although clinical features are similar between eating disorders in older people and the younger population, there are differences in the psychological mechanisms that distinguish eating disorders in the elderly (Lapid 2010). The categories have changed in DSM-5 (American Psychiatric Association 2013), and EDNOS is no longer present. DSM-5 now categorises: anorexia nervosa; bulimia nervosa; pica; rumination disorder; avoidant/restrictive food intake disorder; other specified feeding or eating disorder (OSFED); and unspecified feeding or eating disorder.

OSFED is described as 'feeding or eating behaviours that cause clinically significant distress and impairment in areas of functioning, but do not meet the full criteria for any of the other feeding and eating disorders' (American Psychiatric Association 2013). This includes atypical anorexia (Box 4). The category 'unspecified feeding or eating disorder' would include those whose behaviour causes clinically significant distress but does not meet criteria for the other disorders (Eating Disorders Victoria 2016).

\section{Causes of disorder eating}

Although it is important not to miss an eating disorder in an older person there are a number of other causes of weight loss in the elderly. These can be physical, psychological or social, and clinicians should be mindful of them in all patients, especially those unable to communicate pain or distress.

\section{Physical health problems}

A large range of physical problems can affect eating and weight. These include gastrointestinal, cardiovascular and pulmonary problems as well as cancer. It has been estimated that $75 \%$ of adults aged 89 and over have significantly impaired gustatory sense of smell or taste (Dudrick 2013).
The elderly have reduced saliva production, which can in turn lead to a dry mouth, poor oral and dental hygiene and ultimately reduced food intake. There is also the possibility of poorly fitting dentures, missing teeth, dysphagia and other swallowing difficulties (Johnson 2010a). Furthermore, $50-75 \%$ of older people have other gastrointestinal tract problems such as indigestion and reflux. Older people also have slower muscle actions in their bowels, leading them to feel fuller for longer. These factors combined can have potentially lethal consequences (Dudrick 2013).

Older people are known to be prescribed multiple medications. These can have a huge impact on appetite and whenever possible should be reviewed carefully: although polypharmacy can affect appetite, reducing psychotropic medication can, for example, destabilise previously controlled anxiety (Dudrick 2013). It is not just medications that can cause harm: patients can be frightened by dietary advice. There have been cases of patients so conscious of or frightened by medical advice that they are not sure what they can and cannot eat, leading to dramatically reduced food intake (Lapid 2010). People with diabetes have been known to experience weight loss due to overzealous glucose control (Schaeffer 2016).

Causes of reduced intake will vary depending on the patient, their medical history, their medications and their mobility status (Dudrick 2013).

\section{Mental health problems}

Mental health conditions are a frequent cause of reduced food intake. One study has shown that $36 \%$ of nursing home residents with unintentional weight loss had depression (Morley 1994). Major depression is the most common psychiatric disorder in older people with eating disorders, and depression itself can affect appetite and intake (Dudrick 2013; Schaeffer 2016).

Dementia can have a large effect on eating and it may present a number of symptoms that make eating more difficult. There can be difficulties with shopping and cooking, forgetting to eat, as well as concentration and motor difficulties that make eating difficult (Johnson 2010b; Alzheimer's Society 2016).

Eating problems in dementia typically begin in the moderate to severe stages of the illness, when people start needing to be fed. Later in the illness swallowing can become uncoordinated and present a risk of choking. Thickened fluids and a pureed diet can be helpful and can increase gastric emptying, thus maximising calorie intake, but there is debate over what is best to do in this situation. One key consideration is the palatability 
of a pureed diet. There should also be caution about introducing permanent swallowing measures (e.g. percutaneous endoscopic gastrostomy (PEG) or nasogastric tube), as swallowing difficulties may be transient, due to illnesses such as pneumonia (Dudrick 2013; DementiaGuide 2016).

As with other older people, the appetite of someone with dementia can be affected by a range of other factors, including medication, depression and pain. It may be harder for somebody with dementia to communicate these problems, which may present as challenging behaviour. Challenging behaviour may be understandable if the person is being given a food that they dislike and they have no other way of communicating this (DementiaGuide 2016).

Having dementia does not necessarily mean that food intake will decrease. One study reported that $21 \%$ of people with dementia have increased food consumption, $22.1 \%$ have decreased food consumption, $11.4 \%$ to have a preference for sweet things and $7.6 \%$ become more fussy about food choices (Cullen 1997). In frontotemporal dementia in particular, people can overeat, consume excessive amounts of liquids, alcohol or cigarettes, or try to eat inedible objects (DementiaGuide 2016).

\section{B0X 5 Case vignette: anorexia nervosa}

Catherine, aged 89, was referred to a service for high-risk eating disorders by a community dietician with concerns that she had a BMI of 14 and was resisting attempts to help improve her diet. Catherine acknowledged that looking good was always important to her, but there was no obvious evidence of body image problems or dwelling on her looks. She described herself as quite rigid and set in her ways. She often made comments about other people gaining weight. She had been living in a residential then nursing home for almost 20 years. She has always tried to control her food intake. In the 8 months before referral, her weight had dropped from $29 \mathrm{~kg}$ to $26 \mathrm{~kg}$. She was unable to identify any reasons for triggers for her low weight and in her opinion she had eaten well in the past few days, although she acknowledged that she sometimes refused food for several days and she could not say why. She was fussy about what she ate and moved most of her food to the side of her plate, eating just the small portion that she had assigned to herself. Staff had noticed that over the past few months she had been less sociable than usual. She stopped going out, saying that the weather was too bad, which was unusual for her previous busy lifestyle. As a result of her eating disorder she is often severely constipated.

It seemed that she was using anorexia nervosa to control her environment. She accepted help from the local team and responded to antidepressant therapy.

\section{Social factors}

Social issues may stop people eating. As people get older they may find it harder physically or financially to shop or cook for themselves. For some older individuals, refusal to eat may be their only remaining means of control. It may be a protest against being accommodated in, for example, a nursing home. Or it may be a protest against, or means of controlling, carers or relatives (Box 5). It could even be an attempt at suicide. Unfortunately, we also have to be mindful of elder abuse, in which carers deliberately withhold food (Dudrick 2013; Schaeffer 2016).

\section{Identifying eating disorders}

It can be difficult to identify eating disorders in older people. As discussed earlier, weight loss could be a sign of an undiagnosed medical condition, so a careful history should be taken. Investigations should include blood tests (including a thyroid function test). Creating a timeline and using the SCOFF questionnaire might identify an eating disorder (Lapid 2010). Psychosis and cognitive disorders can resemble anorexia nervosa or bulimia nervosa, but the absence of a desire to be thinner, weight preoccupation or body image distortion will distinguish them from true eating disorders (Dudrick 2013). It is also possible for people to have an eating disorder and another condition: one review found that $60 \%$ of elderly people with an eating disorder had a comorbid psychiatric illness, most commonly major depression (Lapid 2010).

SCOFF is a screening test of five questions designed to allow early detection of eating disorders in people with unexplained weight loss (Box 6). It is not diagnostic, but two or more positive answers should raise the index of suspicion and needs to be followed by more detailed assessment. It has high sensitivity, although its focus on the fat-thin dichotomy may not take into account different ways of thinking about body image and weight among men and women, which might lead to gender bias. SCOFF has been validated in a multiethnic general practice population that included male and female patients and patients over the age of 65 (Solmi 2015), although the number of patients over 65 in the validation study was quite small. There are no studies validating its use specifically in an elderly population.

\section{Treatment}

\section{Pharmacological and psychological interventions}

Management of eating disorders and comorbid psychiatric conditions should focus on a combination 
of pharmacological and behavioural interventions (Lapid 2010; Dudrick 2013; ANRED 2016). Working to overcome psychological problems is more effective than focusing on food choice and addressing weight loss. Supportive counselling can help the individual to cope with perceived loss, anger, lack of purpose, family conflicts and low self-esteem. Depression can be treated with medication, but the treatment of anorexia should revolve around psychotherapy. Hearing and vision should be optimised to ensure that cognitivebehavioural therapy or other psychotherapy are as effective as possible, but cognitive impairment may affect ability to undertake such therapies. It can be helpful to discuss normal and natural age-related physiological changes such as waist thickening and hip enlargement, which in some cultures are a seen as sign of wisdom or experience (ANRED 2016).

\section{Care planning}

In care planning, it can be useful to ask, 'What do you value?' and 'How does your eating disordered behaviour affect the behaviour you value?'. These questions elicit motivation to change (Lapid 2010).

\section{Physical care}

Whatever the cause of weight loss it is important to look after the person's physical health (Lapid 2010). There have been cases of WernickeKorsakoff syndrome in patients with anorexia nervosa (McCormick 2011), but all patients with nutritional deficiency are at risk. It can be useful to involve dieticians and consider removing dietary restrictions on, for example, intake of salt and foods high in cholesterol (Dudrick 2013).

\section{Families as support}

As with younger adults, families may play a key role in treatment. It can be helpful to involve

\section{B0X 6 The SCOFF questions}

Do you make yourself Sick because you feel uncomfortably full?

Do you worry you have lost Control over how much you eat?

Have you recently lost more than $\mathbf{O n e}$ stone in a 3-month period?

Do you believe yourself to be Fat when others say you are too thin?

Would you say that Food dominates your life?

(Morgan 1999, reproduced with permission of BMJ Publishing Group families and help them understand that the patient is not just being stubborn, that an eating disorder is a potentially lethal mental illness and that force feeding can aggravate or worsen the condition. With older people it is likely to be their spouse or children involved rather than parents (Lapid 2010; Dudrick 2013).

\section{Day programmes}

Day programmes can be helpful, ensuring that people dine with others, become more socially active and have the opportunity to participate in a physical rehabilitation programme, all of which can increase appetite (Dudrick 2013).

\section{Practical support and advice in dementia}

There are lots of societies that give useful information and practical tips for people with dementia-related eating disorders and their families. Families and carers are advised to provide regular snacks or small meals rather than set meal times. Also, individuals may no longer recognise the food on their plate, so showing them pictures to stimulate memories and explaining what the food is may help. In earlier stages it might be more useful to help someone with their food shopping rather than take away their independence and cook for them. If they are providing meals for themselves, make sure they have all the funding they are entitled to, for things such as meals on wheels. Family members can monitor if the kitchen has been used recently, if weight has been lost or if being hungry or going shopping have been mentioned recently (Johnson 2010b; Alzheimer's Society 2016).

\section{Barriers to treatment}

There are differences in treating older people with eating disorders, including significant barriers to treatment that might not affect younger people.

\section{Shame and embarrassment}

Older people may be ashamed or embarrassed at having a disorder more commonly associated with the young (Maine 2016).

\section{Multi-aged treatment groups}

Older women may particularly fear being put into a treatment group with adolescents and young adults that they cannot relate to. This may cause more shame or guilt, as they may feel they should be role models for younger girls, taking on a mothering role and focusing their energies on taking care of others rather than on themselves. However, older people may be more able to focus on their health and well-being and have motivations 


\section{MCO answers}

1 b 2 c $\quad 3$ e 4 b 5 ? that younger people do not have, such as children and grandchildren (Maine 2016; Schaeffer 2016).

\section{Comorbidities}

A number of related problems may need to be addressed. Eating disorders can go undetected as they develop and persist under the cover of illnesses such as affective disorders, psychosis, obsessive-compulsive disorder and dementia (Dudrick 2013).

Potential comorbid problems include (ANRED 2016; Maine 2016):

- use of or addiction to cocaine or other stimulants used in weight control, as well as misuse of alcohol (women with eating disorders are 5 times more likely to misuse drugs or alcohol, and women with drug and alcohol problems are 11 times more likely to have an eating disorder; Maine 2016)

- prescription drugs which may be used to numb emotional pain

- consequences of excessive exercise

- unnecessary plastic surgery

- depression and anxiety.

\section{Prognosis}

As with younger adults, the prognosis varies. Some will recover, some will improve and some will continue along a chronic course. An older body cannot take as much abuse so treatment should begin as soon as possible (ANRED 2016).

\section{Eating disorders in men}

Across the population, the average age at death from anorexia is 69 in females and 80 in males: an unexpected finding given the common perception that anorexia is an illness of the young. The most common complication is bowel dysfunction; the most disabling is pain from multiple osteoporotic fractures. Presentation to services may be as much related to affect as to physical complaint; therefore, clinicians should always screen for depression. After the age of 45 , new presentations are more common in men: the female:male ratio rises from 9:1 to 8:2. And acquiring a diagnosis can be very difficult for men (Hewitt 2001).

\section{Conclusions}

Clinicians should not forget that there are a number of causes for weight loss in elderly people. Eating disorders are becoming more common and it is important that they are not missed, especially given the potential for the related higher morbidity and mortality among older people.

\section{References}

Alzheimer's Society (2016) Eating and Drinking. Alzheimer's Society (https://www.alzheimers.org.uk/info/20029/daily_living/10/eating_and_ drinking). Accessed 3 May 2017

American Psychiatric Association (2013) Diagnostic and Statistical Manual of Mental Disorders (5th edn) (DSM-5). APA.

ANRED (2016) Eating Disorders and Older People. ANRED (Anorexia Nervosa and Related Eating Disorders) (https://www.anred.com/elder. html). Accessed 3 May 2017.

Cullen P, Abid F, Patel A et al (1997) Eating disorders in dementia. International Journal of Geriatric Psychiatry, 12: 559-62.

DementiaGuide (2016) Symptom Library: What to look for? Eating. DementiaGuide (https://www.dementiaguide.com/symptomlibrary/phys icalchanges/?pageContent=eating). Accessed 3 May 2017.

Dudrick S (2013) Older clients and eating disorders. Today's Dietician, 15 (11): 44 (http://www.todaysdietitian.com/newarchives/110413p44. shtml).

Eating Disorders Victoria (2016) Classifying Eating Disorders - DSM-5. EDV (http://www.eatingdisorders.org.au/eating-disorders/what-is-aneating-disorder/classifying-eating-disorders/dsm-5). Accessed 3 May 2017

Gagne D, von Holle A, Brownley K, et al (2012) Eating disorder symptoms and weight and shape concerns in a large web-based convenience sample of women ages 50 and above: Results of the gender and body image (GABI) study. International Journal of Eating Disorders, 45: $832-44$

Hewitt PL, Coren S, Steel GD (2001) Death from anorexia nervosa: age span and sex differences. Aging and Mental Health, 5: 41-6.

Johnson J (2010a) Eating disorders and associated digestive problems. Eating Disorder Expert (http://www.eatingdisorderexpert.co.uk/eatingdisorders-associated-digestive-problems.html). Accessed 3 May 2017.

Johnson J (2010b) Eating disorders and dementia. Eating Disorder Expert (http://www.eatingdisorderexpert.co.uk/eating-disorders-dementia. html). Accessed 3 May 2017

Lapid MI, Prom MC, Burton MC, et al (2010) Eating disorders in the elderly. International Psychogeriatrics, 22: 523-36.

Maine MD (2016) Body image despair and eating disorders: what's age got to do with it? National Eating Disorders Association (http://www. nationaleatingdisorders.org/whats-age-got-do-it). Accessed 3 May 2017

Mangwet-Matzek B, Rupp C, Hausmann A, et al (2006) Never too old for eating disorders or body dissatisfaction: a community study of elderly women. International Journal of Eating Disorders, 39: 583-6.

Marshall CE, Lengyel CO, Menec VH (2014) Body image and body work among older women: a review. Ethnicity and Inequalities in Health and Social Care, 7: 196-210.

McCormick L, Buchanan J, Onwuameze 0, et al (2011) Beyond alcoholism: Wernicke-Korsakoff syndrome in patients with psychiatric disorders. Cognitive and Behavioural Neurology, 24: 209-6.

Morgan JF, Reid F, Lacey JH (1999) The SCOFF questionnaire: assessment of a new screening tool for eating disorders. BMJ, 319: 1467

Morley JE, Kraenzle D (1994) Causes of weight loss in a community nursing home. Journal of the American Geriatric Society, 42: 583-5.

Schaeffer J (2013) Goodbye EDNOS, hello OSFED (blog) (http://www. jennischaefer.com/blog/eating-and-body-image/goodbye-ednos-helloosfed-subthreshold-and-atypical-eating-disorders-in-dsm-5). Accessed 3 May 2017.

Schaeffer J (2016) Elder eating disorders: surprising new challenge. Today's Geriatric Medicine (http://www.todaysgeriatricmedicine.com/ news/exclusive 0409 03.shtml). Accessed 3 May 2017.

Solmi F, Hatch SL, Hotopf M, et al (2015) Validation of the SCOFF Questionnaire for Eating Disorders in a multi-ethnic general population sample. International Journal of Eating Disorders, 48: 312-6. 
MCQs

Select the single best option for each question stem

1 According to current research, the percentage of women aged $30-74$ who are dissatisfied with their weight is:

a $20 \%$

b $70 \%$

c $62 \%$

d $31 \%$

e $11 \%$

\section{Which of the following is correct about} diet intake in dementia?

a intake is always decreased

b intake is not affected

c $21 \%$ have increased food consumption

d $90 \%$ have reduced food consumption

e people become less fussy.
3 Assessment of disordered eating in the elderly should include:

a socioeconomic factors

b comorbidities

c polypharmacy

d cognitive impairment

e all of the above.

4 Barriers to treating eating disorders in the elderly include:

a a supportive family

b shame and embarrassment

c younger participants in treatment groups

d lack of exercise

e all of the above.
5 More successful treatment of eating disorders in the elderly contains:

a routine admission to hospital

b cognitive-behavioural therapy

c antidepressants

d antipsychotics

e combined pharmacological and behavioural intervention. 